\title{
Reliability of Indigenous Employment Estimates
}

\section{Boyd Hunter and John Taylor}

$\mathrm{S}$ ince 1971, the main vehicle for establishing a measure of the labour force status of Indigenous Australians has been the five-yearly Census. For the total population, census data are complemented by inter-censal estimates of labour force status derived from the Australian Bureau of Statistics (ABS) Labour Force Survey (LFS) first instituted in 1964. This long-standing commitment to data gathering reflects the importance of employment, unemployment, and labour force participation rates as key national indicators of social and economic wellbeing.

To the extent that Indigenous people have formed part of the sample for the LFS and have participated in the process, they have always been included in the ensuing statistical profile. However, it was not until 1994, in the March survey round, that a question was added to enable the separate identification of Indigenous people within the sample. This practice has subsequently been repeated annually in each February survey. Thus, for one month in each of the past six years, the ABS has gathered statistics that provide for the calculation of Indigenous labour force status, although they have only recently released these data as official, albeit experimental, estimates (ABS, 2000).

From the perspective of policy evaluation, considerable interest surrounds these latest available official measures of Indigenous economic status. As annual estimates, they offer the possibility of establishing trends in labour force status that are more aligned - at least more so than are census data - with identifiable policy shifts and macroeconomic shocks. The time series charted from the sequence of survey results is also suggestive, at least at face value, of a sizeable decline in the Indigenous unemployment rate since the mid 1990s, and a current upward trend in employment levels.

These apparently positive results are potentially significant indications for policy and raise a number of pertinent questions. They suggest, perhaps, that improvement is at long last emerging. They possibly reflect the success of the Indigenous Employment Policy. They may be a consequence of macroeconomic, or of microeconomic change. Previous research has found little if any link between macroeconomic change and Indigenous labour force status (Altman and Daly, 1993) - do the results of the LFS suggest otherwise?

It appears that policy-makers are already responding to this new source of data. For example, in its final submission to the Commonwealth Grants

Boyd Hunter and John Taylor are Fellow and Senior Fellow respectively in the Centre for Aboriginal Economic Policy Research at The Australian National University. 
Commission's (CGC) Indigenous Funding Inquiry, the Department of Employment, Workplace Relations and Small Business proposes that key indicators of Indigenous labour force status should be calculated at national, State and regional levels using data from the LFS (CGC, 2000:9). This same submission also implies that previous estimates of labour force status based on projections from the 1996 Census, such as Taylor and Hunter (1998), should be superseded by the 'current' estimates provided by the LFS (CGC, 2000:10). Such a statement affords a degree of legitimacy to the LFS estimates that requires testing.

Accordingly, this paper aims to evaluate critically the estimates of Indigenous labour force status with a view to establishing their reliability, and hence their utility for policy analysis.

\section{History of Official Measures}

The lack of regular and accurate labour force estimates has been a long-standing and recurring concern of Indigenous affairs policy-makers (Altman, 1992:2-4). Lack of timeliness in the availability of information on the Indigenous population has been noted in a number of major reviews of Indigenous economic status including: the Miller Review of Aboriginal employment and training programs (Commonwealth of Australia, 1985); the Royal Commission into Aboriginal Deaths in Custody (Commonwealth of Australia, 1991); the Academy of Social Sciences workshop on Aboriginal employment equity (Altman, 1991:168-9); and the Council for Aboriginal Reconciliation (CAR) workshop on benchmarking service delivery for Indigenous Australians (CAR/CAEPR, 1997).

Indeed, it was the dearth of information with which to inform the Royal Commission into Aboriginal Deaths in Custody that caused the Commissioner to recommend a special national survey of the Indigenous population (Commonwealth of Australia, 1991, Vol. 2:62). This recommendation resulted in the 1994 National Aboriginal and Torres Strait Islander Survey (NATSIS) that provided the first inter-census estimates of Indigenous labour force characteristics. Coincidentally, in 1993, the ABS made a decision to include a question on Indigenous identity in the March 1994 LFS. Indigenous identity was also sought in the 1995 National Health Survey (NHS), which includes the standard question on labour force status.

Thus, there are now four ABS collections from which national statistics on Indigenous labour force status may be derived and charted - the Census, the NATSIS, the NHS and the LFS. Obviously, the greatest precision is associated with data from the census that provides a full enumeration of the self-identified Indigenous population.

Although the statistics available from the four collections are based on the same underlying standard International Labour Organisation definitions and concepts, there are differences in methodologies and definitions that affect the comparability of data (ABS, 2000:2). 
Table 1: Indigenous Labour Force Status, 1971-2000

\begin{tabular}{lcccc}
\hline & & $\begin{array}{c}\text { Employment/ } \\
\text { Population Ratio }\end{array}$ & Unemployment Rates & Participation Rates \\
\hline Census & 1971 & 41.4 & 9.3 & 45.6 \\
& 1976 & 40.7 & 17.8 & 49.5 \\
& 1981 & 35.7 & 24.6 & 47.3 \\
& 1986 & 31.3 & 35.3 & 48.3 \\
& 1991 & 37.1 & 30.8 & 51.4 \\
& 1996 & 40.1 & 22.7 & 50.3 \\
NATSIS & 1994 & 35.9 & 38.2 & 58.0 \\
& & & & \\
NHS & & & 20.6 & 60.3 \\
\multirow{3}{*}{ LFS } & 1995 & 47.8 & & 53.1 \\
& 1994 & 38.3 & 27.8 & 56.5 \\
& 1995 & 44.7 & 20.9 & 55.2 \\
& 1996 & 42.5 & 22.9 & 50.7 \\
& 1997 & 38.9 & 23.3 & 52.2 \\
& 1998 & 39.1 & 25.0 & 50.9 \\
& 1999 & 39.8 & 21.9 & 52.9 \\
\hline
\end{tabular}

Notes: a. The 1995 NHS data refers only to the 15 to 64 year-olds and is not strictly comparable to the other statistics in this table that refer to the population aged 15 years or more. Notwithstanding, NHS data are broadly consistent with the LFS results.

b. The 1996 Census estimate of participation rate increases to 52.7 per cent if the "not stated' category is allocated proportionately across all labour force states (rather than assuming respondents who do not reply are outside the labour force). The LFS publications do not report a category for 'not stated' because respondents are always prompted for a response to this question.

Source: $\quad$ ABS (1995); ABS (1998); ABS (2000); and Daly (1995). The NHS estimates are based on unpublished data.

Despite these problems, Table 1 reveals an employment/population ratio that is remarkably consistent across all four collections. All fall within a range of about 7 percentage points around 40 per cent of Indigenous adults, for the period between 1971 and 2000 (excluding 1986). Thus, using Census and NATSIS data as benchmarks, the LFS estimates appear to be in line with expectations, although they exhibit considerable year-to-year fluctuation, with the most recent results suggesting a substantial improvement in the employment ratio.

As for unemployment rates among Indigenous people, census data are suggestive of an increase in the rate between 1971 and 1986 followed by a subsequent steady decline to 1996. This fall in unemployment rates appears to have continued (from the LFS results), especially considering the 1999 and 2000 survey results. In these estimates of unemployment, the effect of the different survey methodologies is clearly evident (Taylor and Hunter, 2001b). It is also apparent that the NATSIS labour force participation rate is notably above other 
estimates. Notwithstanding, the participation rate appears to have risen and then stabilised at just over 50 per cent.

At face value, then, the LFS estimates look reasonable when benchmarked against other collections, and are thus suggestive of continuing positive trends in Indigenous labour force status as indicated by a rising employment rate and declining unemployment rate. How reliable is this estimation?

\section{Reliability of the Estimates}

As with the results of all sample surveys, estimates from the LFS cannot be accepted simply at face value. They require validation in the context of both sampling and non-sampling errors

\section{Sample size}

The fact that the Indigenous LFS estimates are not drawn from a sampling frame designed to be representative of the Indigenous population adds complexity to the assessment of reliability. For example, although the six-year average Indigenous sample size of 1,066 represents a sampling fraction of the Indigenous population which is roughly equivalent to that set by the LFS for the sample of the total Australian adult population $(0.5 \%)$, the Indigenous sample size has varied each year, ranging from a low of 964 in 1998 to a high of 1,189 in 1997. Within this, the annual sample from sparsely settled areas (Statistical Local Areas with less than 0.057 dwellings per square kilometre) has been subject to greater fluctuation - from a high of 354 in 1994 to a low of 153 in 1998). With such small numbers and high annual variability, it is likely that the estimates will be highly variable at sub-national level.

\section{Geographic distribution of the sample}

A potential source of sampling error derives from the fact that the LFS sample is a multi-stage area sample of private dwellings designed to produce reliable estimates of labour force characteristics of the total population in each State and Territory. Another aim of area sampling is to spatially restrict the sampling frame in order to minimise survey costs.

In sparsely settled areas, the areas sampled are often synonymous with communities, and because of the great distances that exist between communities, the sample becomes geographically clustered with the result that Indigenous respondents in such areas are drawn from a relatively small number of localities. This has implications for the reliability of the sample in remote areas, in particular because high variability can exist between communities in terms of available employment opportunities, especially via the Community Development Employment Projects (CDEP) scheme (Altman and Daly, 1992; Altman, Gray and Sanders, 2000; Altman and Hunter, 1996). The CDEP scheme is a federal government program in which unemployed Indigenous people forgo their entitlements to Newstart Allowance payments but receive the equivalent from a 
local community organisation in return for work. It is distinguished from the Work-for-the-Dole Scheme in having a much longer history (since 1977), in being specific to Indigenous communities and having a broader communitydevelopment component.

The multi-stage nature of the sample also means that annual Indigenous data are drawn each time from a different set of communities, thus adding to variability in the annual movement of the estimates. This point is illustrated by 1996 Census data from two adjacent Aboriginal communities in the Northern Territory. While Barunga had an unemployment rate of 46 per cent and no CDEP scheme, the neighbouring community of Wugularr, which has a CDEP scheme, reported no unemployment. Unfortunately, it is not possible to say which types of community (CDEP or non-CDEP) are included in the sample each year as the ABS does not provide such information.

The ABS's weighting procedure (based on Census counts) attempts to adjust for the probability of being sampled in a particular area, thus reducing the scope for bias. However, the weighting procedure might still produce predictable 'biases' in the point estimates of employment and unemployment (and possibly even labour force participation), if it failed to take into account the location of CDEP schemes. Over time this problem would manifest itself as volatility in the estimates of labour force status as the sample switched between communities with and without CDEP schemes. This volatility would depend on how many and which communities are being sampled rather than on the number of respondents.

\section{Sample timing}

Since 1995, the data on Indigenous labour force status has been drawn from the February LFS. February is a highly transitional month in labour market terms and therefore one of the most unstable months of the year to collect information on job seekers. Large numbers of youth, in particular, are about to alter their labour force status by entering the higher education sector, and this presents a severe problem for the interpretation of results. Centrelink data on unemployment indicate that unemployment is much higher in the first few months of the year with many exstudents claiming unemployment benefits before returning to education. It is not possible to seasonally adjust LFS data on Indigenous people since it is only available for one month each year.

Another timing-related issue is that while the estimates are currently based on a single month sample only, from 2002 it is proposed that they be based on a 12-months sample, thus producing 'annualised' estimates (ABS, 2000:2). The ABS calculates that this strategy will effectively increase the Indigenous sample size by 50 per cent with a corresponding reduction in standard errors of around 30 to 40 per cent. However, this methodology raises questions about how monthly data is combined over time to measure unemployment and employment at a particular point in time. For example, the LFS is a rolling sample that replaces one-eighth of the sample every month. Given that monthly data include different people in the various months, it is not clear how the methodology for combining 
the data will address issues about the duration of employment and unemployment for various respondents. If people move in and out of employment, then this will also have to be taken into account. That is, in order to produce annualised estimates, one has to make crucial assumptions about the ongoing labour force status of respondents who are no longer in the sample.

\section{Non-sampling errors}

Non-sampling errors mainly relate to the incorrect or inaccurate reporting of information that inevitably occurs as a consequence of the interaction between respondents and interviewers administering household survey questionnaires. In surveying Indigenous households, ABS experience has highlighted the significance of non-sampling error for this population, especially in sparsely settled areas (ABS, 1999). One aspect of this, having particular relevance to the LFS results, is the difficulty of applying mainstream notions of work and unemployment in a cross-cultural setting. From the standpoint of the Indigenous domain, official indicators have been described as ethnocentric and consequently low in content validity, ambiguously defined and conceptually inadequate (Smith, 1995).

A related issue is the varying degree to which participants in the CDEP scheme may consider themselves employed according to the LFS definition. Following a review of the CDEP scheme in 1997 a series of administrative reforms were implemented that placed emphasis on the scheme as an employment program aimed at equipping participants for mainstream work (Spicer, 1997). Part of this reform involved shifting non-working participants from the scheme into the ambit of the social security system and their replacement by working participants (Sanders, 2000). Prior to this, participation in the scheme did not necessarily equate with employment according to LFS criteria and it is estimated that as many as 40 per cent of scheme participants were not employed (Taylor and Bell, 1998:44-5). According to the Aboriginal and Torres Strait Islander Commission (ATSIC), which administers the scheme, participation is now synonymous with paid employment and, in theory at least, all registered participants would be likely to be classified by the LFS as employed. Assuming this to be the case, the effect of administrative reforms nationally has been to raise estimated levels of Indigenous employment through the CDEP scheme from around 21,000 in 1998 to 31,000 in 1999 (Table 2).

As background to assist in the interpretation of its Indigenous LFS estimates, the ABS reports the number of CDEP scheme participants each year from 1994 to 2000 as at June 30 (ABS, 2000:13). These are shown in Table 2 alongside estimates of the number of CDEP participants who would be classified as employed according to ABS definitions (Taylor and Hunter, 2001a). Administrative data on CDEP are also reported for 1 February each year to maximise comparability with the labour force estimates in ABS (2000). Given that the ATSIC data and Table 4.1 in ABS (2000) are from the same administrative source, it is not surprising that there is little difference in their 
participant numbers. However, compared to the adjusted estimates of those who might be classified as employed as a consequence of their participation in the scheme, the focus on participant numbers alone produces a misleading impression, suggesting low growth in employment due to CDEP in recent years. While some confusion may remain among CDEP participants regarding their labour force status (Altman and Johnson, 2000), it is likely that non-sampling error from this source will tend to decline in significance as participants are increasingly employed under 'no work, no pay' rules.

Table 2: Comparative CDEP Estimates, 1994-2000

\begin{tabular}{lccc}
\hline & CDEP Employed & CDEP participants & \\
\cline { 3 - 4 } & $\begin{array}{c}\text { Taylor and Hunter (2001a) } \\
\text { (30 June) }\end{array}$ & $\begin{array}{c}\text { ABS (2000) } \\
\text { (30 June) }\end{array}$ & $\begin{array}{c}\text { ATSIC } \\
(1 \text { Feb) }\end{array}$ \\
\hline 1994 & NA & 24,100 & 22,178 \\
1995 & NA & 27,000 & 24,107 \\
1996 & 18,656 & 28,400 & 26,217 \\
1997 & 19,974 & 30,000 & 26,442 \\
1998 & 21,228 & 30,300 & 30,007 \\
1999 & 31,650 & 31,900 & 30,738 \\
2000 & 32,220 & 30,600 & 31,050 \\
\hline
\end{tabular}

Note: a. ATSIC figures for 1991-99 are from CDEP Finance spreadsheets, and show actual CDEP participation for February in each year. The figure for 2000 is from CDEPManager, and shows actual participation at 1 February 2000.

Sources: Taylor and Hunter (2001a); Table 4.1 in ABS (2000); ATSIC administrative data.

\section{Confidence Intervals for Changes in Indigenous Unemployment Rates}

The standard errors reported in ABS (2000) are for the number in each labour force status for the Indigenous and non-Indigenous populations. Since most policy analysts are interested in the variability of unemployment rates, employment/population ratios and participation rates, the standard errors for the relevant ratios have to be manipulated to obtain appropriate measures of reliability. Taylor and Hunter (2001b) document this manipulation and provides the methodology for calculating standard errors of the difference or change between two rates.

Using these standard errors it is possible to calculate the 95 per cent confidence intervals for annual movements in unemployment rates (Figure 1). If an unemployment rate in an adjacent year is outside a confidence interval, then we can be 95 per cent confident that there was a significant change in the unemployment rate.

It is difficult to compare the 1994 estimate to other unemployment rates given that it was based on the March, rather than the February, round of the LFS. If one ignores the 1994 estimate, the only statistically significant change in unemployment rates was for the 1999-2000 period. That is, Indigenous 
unemployment between 1995 and 1999 was about 22 per cent plus or minus about 4 percentage points. The lowest overall unemployment rate recorded was 17.6 per cent in February 2000. In effect, this means that no statistical significance can be attributed to any of the estimated changes in unemployment rates for most of the period for which Indigenous data are available from the LFS.

Figure 1: Reliability of LFS Estimates of Indigenous Unemployment

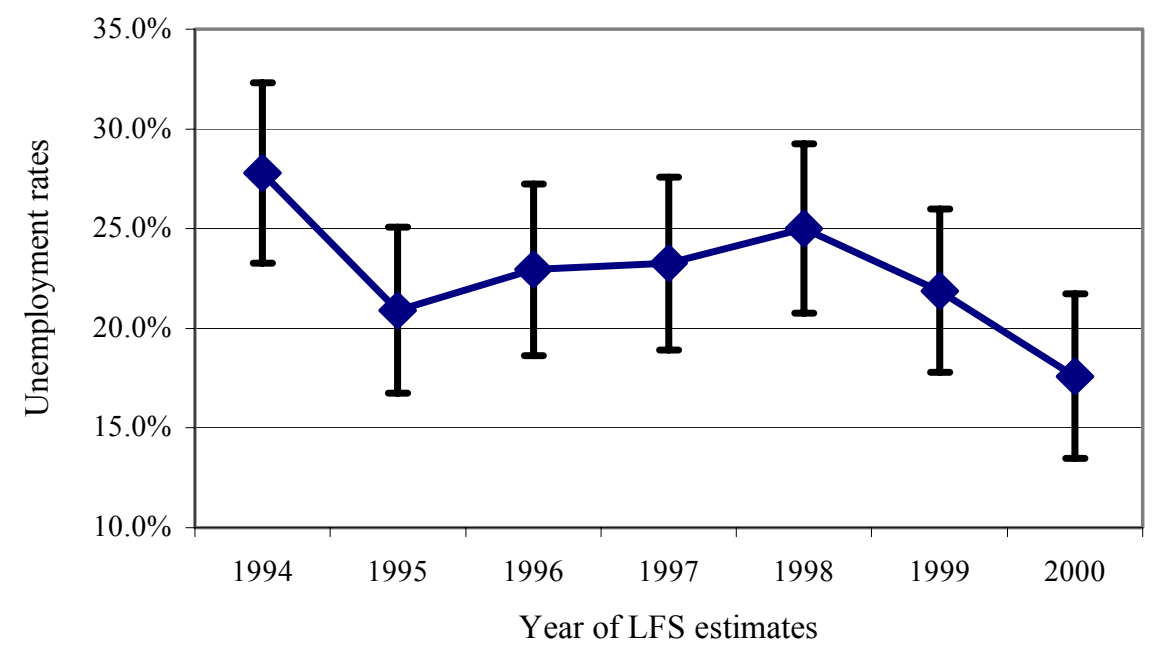

Source: ABS (2000) and Authors' calculations.

The standard errors for non-Indigenous labour force status tend to be much lower than those for the Indigenous population - with non-Indigenous unemployment rates having a relative standard error about five times less than those in the Indigenous data. Consequently, general improvements in Australian unemployment rates in the second half of the 1990s did not translate into significant improvements in Indigenous unemployment because of the unreliability of LFS estimates of the latter.

\section{Benchmarking Indigenous Unemployment Rates}

Another means of testing the reliability of the Indigenous estimates is to compare them to the number of unemployed registered at Centrelink offices. Table 3 facilitates this comparison by indicating the number of Centrelink clients who identified as Indigenous in February of 1999 and 2000 and who, as a result of their receipt of New Start Allowance (NSA) and certain Youth Allowances (YA), could be expected to declare as unemployed in the LFS. 
Table 3: Comparative Levels of Indigenous Unemployment

\begin{tabular}{lccc}
\hline & NSA/YA(o $)^{\mathrm{a}}$ & ABS (2000) & Taylor and Hunter (2001a) \\
\hline Feb-99 & 30,186 & 27,700 & \\
Jun-99 & 29,106 & & 30,200 \\
Feb-00 & 31,866 & 23,700 & \\
Jun-00 & 31,095 & & 27,200 \\
\hline
\end{tabular}

Note: a. The populations include customers who received NSA or Youth Allowance (other) YA(o). Customers on YA(o) are those who are unemployed and receiving YA (not fulltime students on YA). The population for June 2000 excludes NSA/YA(o) customers who participate in CDEP programs. The populations are fortnightly populations for each of the periods. The quality of the data used to derive the Indigenous Indicator depends largely on the data that the customers provide (through self-identification). Prior to September 2000 customers on income support payments were not required to provide information on their Indigenous identification. Seasonal effects are usually prevalent from December to February in both Family and Community Services (FaCS) and ABS data (original series). FACS recommends that care should be taken when analysing the trends in the above populations.

Sources: Centrelink's Newstart SuperStar database; ABS (2000); Taylor and Hunter (2001a).

Against the Centrelink data, LFS estimates are lower - by about 2,500 in 1999 and by about 8,000 in 2000 . The obvious conclusion is that the ABS definition of unemployment is more restrictive than that employed in the Centrelink administrative rules for unemployment entitlements, which allow eligible job seekers to also acquire some paid employment. However, since the activity test requires recipients to actively seek jobs in the previous two weeks (using ABS criteria), the Centrelink figures do at least provide a nominal count of the likely upper bound of Indigenous people who might be classified as unemployed by ABS criteria. Given that the only other estimates of Indigenous unemployment for this period (Taylor and Hunter, 2001a) are close to the Centrelink figures for June 1999 and between the LFS and Centrelink levels in June 2000, the LFS estimates appear to occupy the lower bounds of likely levels. To the extent that these sets of unemployment figures bear any relationship to each other, it is interesting to note that the substantial drop in the LFS estimates between 1999 and 2000 does not appear to be reflected in a similar decline in the Centrelink figures. It does, however, match the decline in unemployment levels simulated by Taylor and Hunter, who provide the only other available set of annual inter-censal estimates (Figure 2).

Although the LFS estimates are unreliable, the simulated unemployment rates are always within the 95 per cent confidence intervals presented in Figure 1. Clearly, the LFS estimates are consistent with the hypothesis advanced in Taylor and Hunter (2001a) that administrative changes in the CDEP scheme are the major factor behind recent changes in Indigenous labour force status. 
Figure 2: Benchmarking LFS Estimates of Indigenous Unemployment Rates

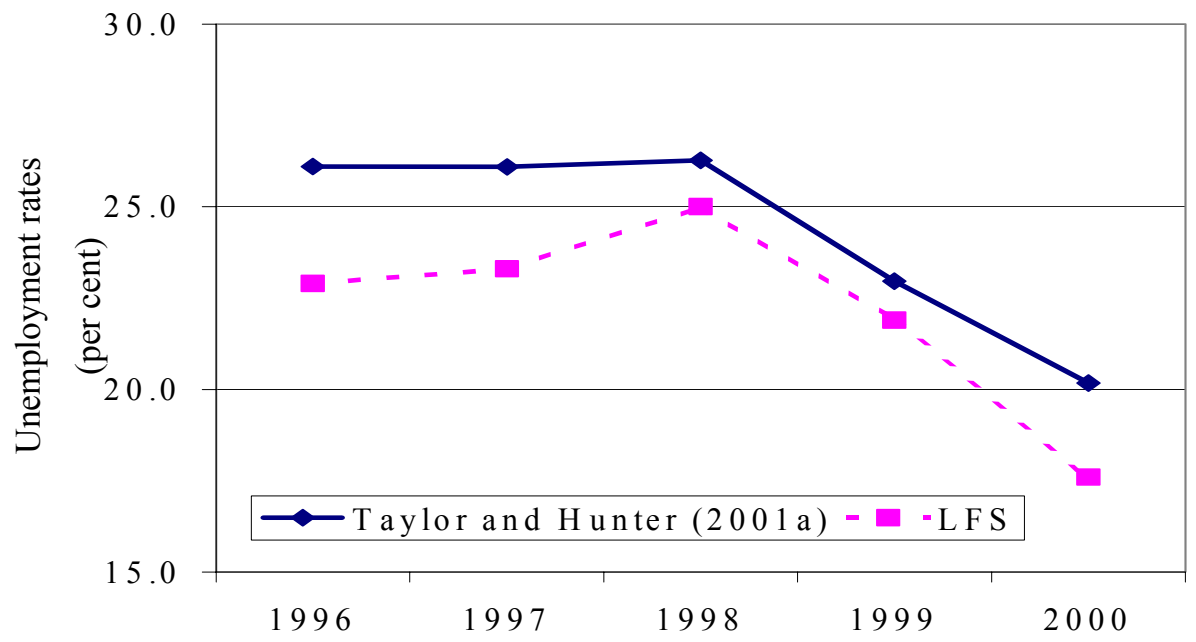

The Taylor and Hunter simulation uses census data to control for demographic changes (that is, the large numbers of Indigenous youth entering the labour market), to make adjustments to account for recent CDEP scheme reforms and to hold employment growth at the 1991-96 rate. Therefore, despite the difference in timing of the ABS and the Taylor and Hunter estimates (in February and June respectively), the LFS results are explicable by recent changes in the labour market and CDEP policy. There is no need to resort to explanations that rely on the effect of active labour market policy or some form of trickle down of macroeconomic growth. Indeed, it could be argued that the Indigenous Employment Policy was implemented too recently to have had any impact as yet on unemployment rates. Equally, it has been shown empirically that Indigenous labour force status bears little relation to macroeconomic change (Altman and Daly, 1993).

\section{Indigenous Labour Force Status Across Areas}

The focus in the previous section was on unemployment rates; however, it is also possible to use the LFS to describe trends in employment/population ratios and participation rates. Furthermore, all three measures of labour force status can be examined separately for the three types of geographic areas used by the ABS (2000). This geographic breakdown is important because of concern about the reliability of LFS estimates for sparsely settled areas. Table 4 presents these labour force status indicators, while Table 5 (below) reports the annual movements in these indicators and the statistical significance of any changes. 
Table 4: Indigenous Labour Force Status by Area, 1994-2000

\begin{tabular}{lrrrrrrr}
\hline & 1994 & 1995 & 1996 & 1997 & 1998 & 1999 & 2000 \\
\hline & & \multicolumn{7}{c}{ Employment/population ratios } \\
Capital city & 48.2 & 46.5 & 42.8 & 38.4 & 45.0 & 46.4 & 48.2 \\
Sparsely settled & 29.1 & 50.1 & 47.3 & 40.9 & 28.0 & 34.8 & 26.5 \\
Balance of State & 35.8 & 41.7 & 40.7 & 38.5 & 39.6 & 37.6 & 46.9 \\
Total Indigenous & 38.3 & 44.7 & 42.5 & 38.9 & 39.2 & 39.8 & 43.6 \\
& & \multicolumn{7}{c}{ Unemployment rates } & & \\
Capital city & 24.7 & 22.5 & 21.3 & 25.2 & 26.3 & 19.8 & 16.6 \\
Sparsely settled & 4.8 & 5.1 & 4.3 & 11.6 & 10.9 & 0.0 & 9.6 \\
Balance of State & 34.6 & 25.1 & 29.5 & 25.8 & 26.9 & 28.5 & 19.6 \\
Total Indigenous & 27.8 & 20.9 & 22.9 & 23.3 & 25.0 & 21.9 & 17.6 \\
& & & \multicolumn{7}{c}{ Labour force participation rates } & & \\
Capital city & 63.9 & 60.0 & 54.4 & 51.3 & 61.0 & 57.8 & 57.8 \\
Sparsely settled & 30.6 & 52.8 & 49.4 & 46.3 & 31.4 & 34.8 & 29.3 \\
Balance of State & 54.7 & 55.7 & 57.7 & 51.9 & 54.1 & 52.6 & 58.3 \\
Total Indigenous & 53.1 & 56.5 & 55.2 & 50.7 & 52.2 & 50.9 & 52.9 \\
\hline
\end{tabular}

Source: ABS (2000).

Employment ratios have been reasonably stable in non-remote areas but are highly volatile in sparsely settled areas, where they fluctuated between 50.1 per cent and 26.5 per cent. For example, capital cities have had employment ratios hovering around 45 per cent, while the ratio was reasonably stable at around 40 per cent in the balance of State areas. There has been only a slight increase in overall Indigenous employment since 1999. Since employment did not improve substantially in capital cities and declined in sparsely settled areas, the increase can only be driven by changes in the balance of State areas, which includes regional and rural areas. Since many Indigenous communities in such areas are covered by the CDEP scheme, this observation is consistent with the Taylor and Hunter hypothesis reported above.

Unemployment rates in capital cities and 'balance of State' areas declined from a high base in a similar manner to that for the overall distribution (Figures 1 and 2). Much of the decline in unemployment rates appears to be generated outside capital cities, especially in the 1994 to 1995 period.

In contrast, unemployment rates in sparsely settled areas are very low and appear 'random'. They can be explained by the extensive participation in CDEP scheme across remote Australia. However, the fact that the unemployment rate rises, and then falls by 10 percentage points each year between 1998 and 2000 is particularly revealing of underlying problems with the measurement of LFS. Since employment demand is likely to be very weak in such areas, the fall of the unemployment rate to zero in 1999 means that the sample was probably taken exclusively from CDEP communities in that year. That is, the clustered nature of 
the sample is likely to have generated particularly unreliable estimates, and some of their variability will not be picked up by the standard error provided by the ABS. In addition, the small sample of unemployed respondents in such areas, combined with widespread uncertainty among remote Indigenous people as to what constitutes being unemployed (that is, non-sampling errors), makes the unemployment rates particularly unreliable.

The LFS estimates of labour force participation are reasonably similar in capital cities and the balance of State. However, participation in sparsely settled areas in February 2000 appear remarkably low - approximately half that in capital cities (29.3 per cent compared to 57.8 per cent). In contrast, Altman and Gray (2000:7) derive an Indigenous participation rate of 58.3 per cent for areas where Special Indigenous Forms were deployed in the 1996 Census (an area roughly equivalent to the sparsely settled areas). This large disparity between the census-based participation rates and the LFS estimates after 1998 (or indeed the 1994 rates) raises further doubt about the accuracy of the latter, at least in sparsely settled areas. While it is not possible to discount the possibility that labour force participation in such areas fell by almost one-half between 1995 and 2000 (or rose by a similar amount between 1994 and 1995), it seems highly unlikely that this pattern was generated from a random sample, especially in the absence of a plausible hypothesis to explain large changes in both employment and participation in remote areas. For example, it is possible to discount the role of CDEP reforms in depressing the 1994 participation rates because these did not take effect until 1998. In any case, the internal expansion of the CDEP scheme would have a tendency to increase employment and reduce labour force participation simultaneously if non-working participants leave the labour force.

Table 5 provides data on the geography of annual changes in labour force status and indicates whether a change was statistically significant. For example, overall Indigenous employment/population ratios increased significantly in 199495 and 1999-2000, and fell significantly in 1996-97. Interestingly, none of these significant changes coincided with the only significant change in employment in capital cities (1997-98). In contrast, the balance of State areas registered significant increases in employment in the same years that overall Indigenous employment was buoyant. As expected, the changes in sparsely settled areas appear random, with equal numbers of significant increases and decreases in employment, and with the employment ratio in 2000 being roughly equal to that in 1994. It appears that the significance of these statistics is driven by the artificially low standard errors that fail to take account of the effect of 'clustering' and non-sampling errors.

There are no significant changes in Indigenous unemployment rates in capital cities. All the significant changes in unemployment rates have been generated in the balance of State areas, for which the significant changes in unemployment coincide with those in the overall Indigenous unemployment rates. As indicated above the changes in unemployment in sparsely settled areas appears to be generated by the nature of the LFS Indigenous sample. 
Table 5: Significance of Annual Changes in Indigenous Labour Force Status by Area, 1994-2000

\begin{tabular}{|c|c|c|c|c|c|c|}
\hline & \multicolumn{6}{|c|}{ Period over which change in labour force status is measured } \\
\hline & 1994-1995 & 1995-1996 & 1996-1997 & 1997-1998 & 1998-1999 & $1999-2000$ \\
\hline & \multicolumn{6}{|c|}{ Employment/population ratios } \\
\hline Capital city & -1.7 & -3.7 & -4.4 & $6.6^{*}$ & 1.4 & 1.9 \\
\hline Sparsely settled & $21.0 *$ & -2.9 & -6.4 & $-12.9^{*}$ & $6.8^{*}$ & $-8.3^{*}$ \\
\hline Balance of State & $6.0^{*}$ & -1.1 & -2.1 & 1.0 & -2.0 & $9.3^{*}$ \\
\hline \multirow[t]{2}{*}{ Total Indigenous } & $6.4^{*}$ & -2.2 & $-3.6^{*}$ & 0.2 & 0.6 & $3.8^{*}$ \\
\hline & \multicolumn{6}{|c|}{ Unemployment rates } \\
\hline Capital city & -2.2 & -1.2 & 3.9 & 1.1 & -6.5 & -3.2 \\
\hline Sparsely settled & 0.2 & -0.7 & $7.3^{*}$ & -0.7 & $-10.9 *$ & $9.6^{*}$ \\
\hline Balance of State & $-9.5^{*}$ & 4.4 & -3.7 & 1.1 & 1.6 & $-8.8^{*}$ \\
\hline \multirow[t]{2}{*}{ Total Indigenous } & $-6.9^{*}$ & 2.0 & 0.3 & 1.8 & -3.1 & $-4.3^{*}$ \\
\hline & \multicolumn{6}{|c|}{ Labour force participation rates } \\
\hline Capital city & -3.9 & $-5.6^{*}$ & -3.1 & $9.7^{*}$ & -3.2 & 0.0 \\
\hline Sparsely settled & $22.2^{*}$ & -3.4 & -3.1 & $-14.9 *$ & 3.4 & -5.5 \\
\hline Balance of State & 1.0 & 2.0 & $-5.8^{*}$ & 2.2 & -1.6 & $5.7^{*}$ \\
\hline Total Indigenous & $3.4^{*}$ & -1.3 & $-4.4^{*}$ & 1.5 & -1.3 & 2.0 \\
\hline $\begin{array}{l}\text { An as } \\
\text { Test s }\end{array}$ & $\mathrm{k}$ denotes & $\begin{array}{l}\text { t a chang } \\
\text { lated usin }\end{array}$ & $\begin{array}{l}\text { labour forc } \\
\text { methodolo }\end{array}$ & $\begin{array}{l}\text { status was } \\
\mathrm{y} \text { in Taylor }\end{array}$ & $\begin{array}{l}\text { nificant at } t \\
\text { d Hunter (2 }\end{array}$ & $\begin{array}{l}\text { e } 95 \% \text { level. } \\
01 \text { b). }\end{array}$ \\
\hline Source: & & & & & & \\
\hline
\end{tabular}

The annual movement in participation rates is roughly similar to that for employment ratios. One difference is that the significant increase in participation between 1994-95 is driven solely by the large apparent increase in participation in sparsely settled areas. Given the doubt that surrounds these estimates it would be unwise to overestimate their contribution to the overall picture. If one ignores the results for sparsely settled areas, one other difference is that an insignificant fall in participation in balance of State areas in 1996-97 translated into a significant decline in overall Indigenous participation. Also, the significant fall in participation in capital cities in 1995-96 is hidden in the annual changes in overall participation by the countervailing, but insignificant, increase in participation in the balance of State areas. While the inclusion of sparsely settled areas in the overall sample may hide important information on labour force trends, the changes in non-remote participation rates are very small in magnitude and appear to balance out in the medium term.

\section{Policy and Methodological Implications}

Recent publication by the ABS of annual estimates of Indigenous labour force status from the LFS represents an important development in the routine 
monitoring of Indigenous economic status. As they stand, however, the estimates are of limited value for policy analysis. At best, they merely confirm existing understandings of recent labour force trends. At worst, they are unreliable due to high standard errors. In particular, movements of annual rates are statistically insignificant in all but the last two years, thus preventing the establishment of long-term trends. As in other ABS surveys, these results partly reflect sampling problems in sparsely settled areas. The inclusion of remote areas in estimates of overall Indigenous labour force status conceals significant trends in employment and participation rates and generates trends where probably none exist in reality.

Because of these limitations, policy makers should pay attention to the forthcoming Indigenous Social Survey. The ISS Indigenous sample will be much larger than that of the LFS and more regard will be given to Indigenous-specific issues, which will minimise non-sampling errors. It may therefore be prudent to give more weight to the ISS estimates, especially when assessing labour force status in remote Australia.

The key finding of significant decline in unemployment rates since 1998 resonates with an analysis of trends in increasing CDEP scheme employment and with the fact that purely administrative changes to the scheme are likely to have raised overall employment levels over the same period (Taylor and Hunter, 2001a). In other words, it is very unlikely that the recent decline in Indigenous unemployment has formed part of the general labour market trend, as has been demonstrated earlier (Altman and Daly, 1993). Also, the implementation of the Indigenous Employment policy would seem to have occurred too recently to have had any bearing on this result. While some program elements of the Indigenous Employment Policy commenced in July 1999, many of the programs were introduced progressively through the second half of 1999 and early 2000.

Technical issues such as the representativeness of the sample are important for interpreting the published ABS results. One means of ensuring that the sample is representative of the experience of Indigenous people is to augment the LFS with a stratified sample of the Indigenous population, as in the NHS. If the ABS were to deem that the expenditure this entails is not warranted, it would enhance the value of LFS data if more detail on the geographic composition of the sample were published. This would assist in understanding the process and effects of clustering in particular remote Indigenous communities. A nationally augmented sample might also open the possibility of increased use of Indigenous interviewers (Alphenaar, Majchrzak-Hamilton and Smith, 1999), although this would not, in itself, guarantee that response rates and data quality would be acceptable. Hunter and Smith (2000) provide a detailed analysis of the advantages and disadvantages of using Indigenous interviews in a 'longitudinal' context. While the LFS is based a rotating panel, rather than a strictly longitudinal survey, it attempts to collect information on respondents over time and hence will have to deal with a similar set of issues.

It would also aid the interpretation of estimates if more detail were provided for the accurate calculation of standard errors of annual movements in labour force rates. For example, the standard errors for unemployment rates used in this 
paper are potentially inaccurate because no information was provided on the appropriate adjustment factors for the labour force (see Taylor and Hunter, 2001b). While a conservative adjustment was used, this tends to overstate the variability of the labour force and hence understates standard errors of unemployment rates.

\section{References}

Alphenaar, A., G. Majchrzak-Hamilton, and D. Smith (1999), 'Review of Enumeration of Indigenous Peoples in the 1996 Census', Australian Bureau of Statistics ABS, Canberra (Working Paper).

Altman, J. (ed.) (1991), Aboriginal Employment Equity by the Year 2000, CAEPR Research Monograph No. 2, Centre for Aboriginal Economic Policy Research (CAEPR), ANU, Canberra.

Altman, J. (ed.) (1992), A National Survey of Indigenous Australians: Options and Implications, CAEPR Research Monograph No. 3, CAEPR, ANU, Canberra.

Altman, J. and A. Daly (1992), 'The CDEP Scheme: A Census-based Analysis of the Labour Market Status of Participants in 1986', Economic Papers 11(4):32-48.

Altman, J. and A. Daly (1993), 'Do Fluctuations in the Australian Macroeconomy Influence Aboriginal Employment Status?' pp. 165-86 in A. Hodgkinson, D. Kelly and N. Verucci (eds), Responding to Unemployment: Perspectives and Strategies, Labour Market Analysis Program, University of Wollongong, Wollongong.

Altman, J. and M. Gray (2000), 'The Effects of the CDEP Scheme on the Economic Status of Indigenous Australians: Some Analyses Using the 1996 Census', CAEPR, ANU, Canberra (Discussion Paper No. 195).

Altman, J., M. Gray and W. Sanders (2000), 'Indigenous Australians Working for Welfare: What Difference Does it Make?’ The Australian Economic Review 33(4):355-62.

Altman, J. and B. Hunter (1996), 'The Comparative Economic Status of CDEP and Non-CDEP Community Residents in the Northern Territory in 1991', CAEPR, ANU, Canberra (Discussion Paper No. 107).

Altman, J. and V. Johnson (2000), 'The CDEP in Town and Country Arnhem Land: Bawinanga Aboriginal Corporations', CAEPR, ANU, Canberra (Discussion Paper No. 209).

Australian Bureau of Statistics (1995), National Aboriginal and Torres Strait Islander Survey 1994: Detailed Findings, Cat. No. 4199.0, Canberra.

Australian Bureau of Statistics (1998), 1996 Census of Population of Population and Housing: Aboriginal and Torres Strait Islander People, Canberra.

Australian Bureau of Statistics (1999), 'Survey Strategy for Aboriginal and Torres Strait Islander Statistics', Unpublished Report, Canberra.

Australian Bureau of Statistics (2000), Labour Force Characteristics of Aboriginal and Torres Strait Islander Australians: Experimental Estimates from the Labour Force Survey, Cat. No. 6287.0, Canberra.

Australian Bureau of Statistics (2001), 'Estimating the Standard Error (SE) of the Movement in Unemployment Rate for Estimates in the Labour Force Characteristics of Aboriginal and Torres Strait Islander Australians Publication (Cat. No. 6287.0)', Unpublished Paper, Canberra. 
ABS/CAEPR (1996), 1994 National Aboriginal and Torres Strait Islander Survey: Employment Outcomes for Indigenous Peoples, Cat. No. 4199.0, ABS, Canberra.

Commonwealth Grants Commission (2000), 'Commonwealth Grants Commission Indigenous Funding Inquiry, DEWRSB Final Submission’, Submission No. IFI/SUB/0064, Canberra.

Commonwealth of Australia (1985), Report of the Committee of Review of Aboriginal Employment and Training Programs (The Miller Report), AGPS, Canberra.

Commonwealth of Australia (1991), Royal Commission into Aboriginal Deaths in Custody, Vol. 1, (Commissioner E. Johnson), AGPS, Canberra.

Council for Aboriginal Reconciliation and CAEPR (CAR/CAEPR) (1997), 'Towards a Benchmarking Framework for Service Delivery to Indigenous Australians', Proceedings of the Benchmarking Workshop, 19 November, CAR-CAEPR, Canberra.

Daly, A. (1995), Aboriginal and Torres Strait Islander People in the Australian Labour Market, Cat. No. 6253.0, Australian Bureau of Statistics, Canberra (Occasional Paper).

Hunter, B. and D. Smith (2000), 'Surveying Mobile Populations: Lessons from Recent Longitudinal Surveys of Indigenous Australians', CAEPR, ANU, Canberra (Discussion Paper No. 203).

Sanders, W. (2000), 'Adjusting Balances: Reshaping the CDEP Scheme After Twenty Good Years', Paper presented to the CAEPR/Reshaping Australian Institutions Conference on 'The Indigenous Welfare Economy and the CDEP Scheme: Autonomy, Dependence, Self-Determination and Mutual Obligation', ANU, Canberra, 9 November.

Smith, D. (1995), 'Measuring the Contemporary Labour Force Status of Indigenous Australians', Labour Economics and Productivity 7(1):28-48.

Spicer, I. (1997), Independent Review of the Community Development Employment Projects (CDEP) Scheme, Office of Public Affairs, ATSIC, Canberra.

Taylor, J. and M. Bell (1998), 'Making Sense of Census Data: A Components Analysis of Employment Change Among Indigenous Australians', Journal of the Australian Population Association 15(1):35-51.

Taylor, J. and B. Hunter (1998), The Job Still Ahead: Economic Costs of Continuing Indigenous Employment Disparity, Office of Public Affairs, ATSIC, Canberra.

Taylor, J. and B. Hunter (2001a), 'Demographic Challenges to the Future of CDEP' in F. Morphy and W. Sanders (eds), The Indigenous Welfare Economy and the CDEP Scheme: Autonomy, Dependence, Self-Determination and Mutual Obligation, CAEPR Research Monograph No. 20, CAEPR, Canberra, Forthcoming.

Taylor, J. and B. Hunter (2001b), 'Indigenous data from the ABS Labour Force Survey: What Can they Tell Us? ', CAEPR, ANU, Canberra (Discussion Paper No. 214).

The authors gratefully acknowledge helpful comments by Roger Jones, Steven Kennedy, Mardi Dungey and anonymous referees. For advice and assistance on statistical matters, we are indebted to: Harry Kroon, Matthew Cronin and Matthew Berger of the ABS, Luat Vuong and Kortlee Marshall of DfaCS, and Kim Grey of DEWRSB. 